\title{
Effect of Microglial Inflammation in Prion Disease
}

\author{
Yasuhisa Ano ${ }^{1 *}$, Akikazu Sakudo ${ }^{2,3}$ and Takashi Onodera ${ }^{4}$
}

\author{
${ }^{1}$ Research Laboratories for Health Science and Food Technologies, Kirin Company Ltd., Yokohama, \\ Japan. \\ ${ }^{2}$ Laboratory of Biometabolic Chemistry, School of Health Sciences, University of the Ryukyus, \\ Nishihara, Japan. \\ ${ }^{3}$ Faculty of Veterinary Medicine, Okayama University of Science, Imabari, Ehime, Japan. \\ ${ }^{4}$ Graduate School of Agricultural and Life Sciences, University of Tokyo, Tokyo, Japan. \\ ${ }^{*}$ Correspondence: Yasuhisa_Ano@kirin.co.jp \\ https://doi.org/10.21775/cimb.036.001
}

\begin{abstract}
Prion diseases are a group of transmissible fatal neurodegenerative disorders. Neuropathological features of prion diseases include neuroinflammation featuring the infiltration of activated microglia in affected brain areas as well as the accumulation of an abnormal isoform of the cellular prion protein and neuronal loss. Recent studies have elucidated that inflammation in the brain induced by microglia plays an important role in the pathogenesis of neurodegenerative disorders including prion disease. Thus, the regulation of neuroinflammation is key in terms of therapeutic and preventative approaches. The functions of neuroinflammation and microglia in this disease are discussed in this article.
\end{abstract}

\section{Background}

Prion diseases are a group of transmissible fatal neurodegenerative disorders of bovine spongiform encephalopathy (BSE) in cattle, Creutzfeldt-Jakob disease (CJD) in humans, scrapie in sheep, and chronic wasting disease (CWD) in deer and elk. They are caused by the conversion of cellular prion protein $\left(\mathrm{PrP}^{\mathrm{C}}\right)$ into the pathological isoform $\left(\mathrm{PrP}^{\mathrm{Sc}}\right)$ through conformational changes (Prusiner, 1998; Wechselberger, 2002). $\operatorname{PrP}^{\mathrm{Sc}}$ is protease-resistant, and has a higher proportion of $\beta$-sheet structure in place of the normal $\alpha$-helix structure. The accumulation of abnormal forms of prion protein $\left(\mathrm{PrP}^{\mathrm{Sc}}\right)$ is important for developing the disease. Prion disease is neuropathologically characterized by neuronal vacuolation, neuronal loss, astrogliosis, and accumulation of activated microglial cells in affected brain areas (Ironside, 1998). Microglia, the resident macrophages in the central nervous system, are exquisitely sensitive to pathological tissue alterations, undergoing morphological and phenotypic changes to adopt a so-called activated state and perform immunological functions 
in response to pathophysiological brain insults (Ransohoff et al., 2009; Perry et al., 2010). Many studies have demonstrated that the microglia have very diverse effector functions, in line with macrophage populations in other organs (Graeber, 2010). Mounting evidence also indicates that microglial activation contributes to neuronal damage in several neurodegenerative diseases including Alzheimer's disease, prion diseases, Parkinson's disease, multiple sclerosis, and Huntington's disease (Perry et al., 2009; Gonzalez et al., 1999). In prion diseases and other neurodegenerative disorders, microglia can become overactivated and generate reactive oxygen species (ROS), nitric oxide (NO), and cytokines, which can cause vascular damage in addition to neurodegeneration (Block et al., 2007; Garção, et al., 2006; Aguzzi et al., 2006). Inflammation in the CNS accelerates the pathology of neurodegenerative disorders. Thus, neuroinflammation is an attractive target for novel therapeutic approaches. In this review, the roles of microglia in the neurodegenerative and in flammatory process mediated by prion infection are discussed.

\section{Microglial inflammation in the central nervous system}

Microglia are the resident macrophages in the central nervous system (CNS), in which they are ubiquitously distributed, accounting for approximately $10 \%$ of the adult brain cell population and representing the initial and primary immune response (Fig. 3.1A) (Kreutzberg, 1996). Recent studies revealed various functions of microglia and their crucial role in the upkeep of the brain environment. It is reported that microglia play an essential role in neurogenesis and in the extension of neuronal synapses. Microglia remove old synapses and promote neurons in learning-dependent synapse formation through brain-derived neurotrophic factor (BDNF) signalling (Parkhurst et al., 2013).

Activated microglia are able to confer full immune effecter function, allowing them to eradicate the source of brain insult and to restore tissue integrity. This includes neuroprotective functions such as phagocytosis to remove the pathogen and cytotoxic effects via the release of pro-inflammatory mediators and ROS for swift removal of harmful pathogens

A

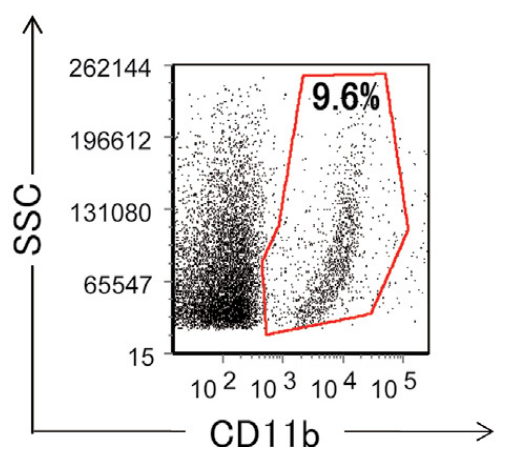

$\mathrm{B}$

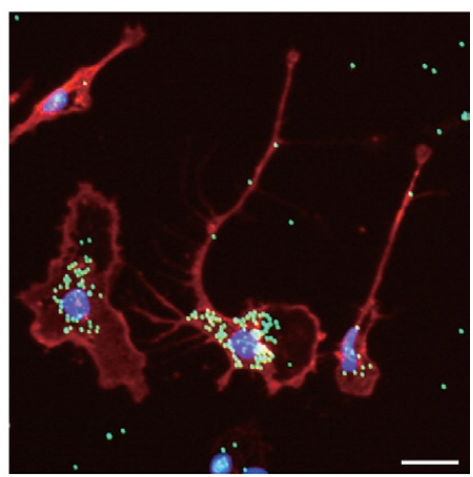

Figure 3.1 Population and phagocytosis of microglia. (A) the rate of microglia (cd11b positive cells) in the brain cells is approximate $10 \%$. (B) microglia showed phagocytic activity and activated microglia released inflammatory cytokines. green shows latex beads, red shows cd11b, and blue shows nuclei. scale bar is $20 \mu \mathrm{m}$. 
(Fig. 3.1B) (van Rossum et al., 2004; Neumann et al., 2006; Imai et al., 2007). Microglia activation occurs following exposure to CNS pathogen and detection of a variety of stimuli such as lipopolysaccharide (LPS), interferon-gamma (IFN- $\gamma$ ), amyloid-beta (A $\beta)$ and other proinflammatory cytokines during injury and disease (Dheen et al., 2007). Activated microglia can be identified and distinguished from their resting phenotype based on a combination of morphological and immunophenotypic changes. This includes a change from their typical ramified morphology to a reactive phenotype characterized by hypotrophy of the cell body, shortened and extensively branched processes (an amoeboid morphology), and significant upregulation of cytoplasmic and membrane molecules (Ransohoff et al., 2009).

To initiate innate immune responses, microglia enhance the expressions of toll-like receptors (TLR) (Bsibsi et al., 2002) and multiple pro-inflammatory mediators such as tumour necrosis factor-alpha (TNF- $\alpha$ ) (Floden et al., 2005), interleukin (IL)-1 (Hartlage-Rubsamen et al., 1999), and IL-6 (Suzumura et al., 1996). The release of various chemokines including macrophage inflammatory protein-1 $\alpha$ (MIP-1 $\alpha$ ) and MIP-1 $\beta$ (Takami et al., 1997), monocyte chemoattractant protein-1 (MCP-1) (Babcock et al., 2003), and also those involved in lymphocyte recruitment suggest that microglial activation is a process that precedes peripheral immune cell recruitment and that it is the first line of innate immunity in the CNS. Meanwhile, microglial cytotoxic functions are increased due to cytokine stimulation by other immune cells with the release of NO• (Banati et al., 1993), such as superoxide (Chan et al., 2007). It was also reported that microglia isolated from prion infected mice showed increased expression of IL- $1 \beta$, TNF- $\alpha$ and CFS1, but not IL-6, IL-10 or TGF- $\beta$, which correlates with disease progression (Vincenti et al., 2015). In addition, a recent study reported new inflammatory genes upregulated early in the prion brain, including genes involved in inflammation, monocyte recruitment and growth regulation (Carroll et al., 2015).

Early post-mortem and histopathological investigations have reported the presence of large numbers of activated microglia in the CNS of patients with neurodegenerative disease including Alzheimer's disease, Parkinson's disease, multiple sclerosis, Huntington's disease, amyotrophic lateral sclerosis (ALS), and prion disease (McGeer et al., 1988a,b; Raine, 1994; Banati et al., 1998; Li et al., 1996; Sitte et al., 2001; Sapp et al., 2001), although it remains inconclusive whether they play a role in pathogenesis or simply appear as a consequence of the disease process. The role of microglia as contributors to the progression of neurodegenerative disease was first proposed in Alzheimer's disease (Griffin et al., 1989), where long-term intake of non-steroidal anti-inflammatory drugs (NSAIDs) was associated with a reduced risk of developing the disease (Etminan et al., 2003; Vlad et al., 2008). Although a harmful role for microglia in neuroinflammation is a popular view, there is mounting evidence that points to the contrary, that is, that microglia are in fact neuroprotective in these diseases (Hines et al., 2009; Power et al., 2009).

\section{CXCR3 accelerates prion replication but prolongs survival times after prion infection}

It has recently been reported that the chemokine receptor CXCR3 prolongs the survival period in prion infection (Riemer et al., 2008). In neurodegenerative disease, elevated chemokine expression levels have been observed in numerous pathologies of the brain. During prion infection in the CNS, the chemokines chemokine (C-C motif) ligand 2 (CCL2) (Felton et al., 2005), CCL3 (Lu et al., 2004; Riemer et al., 2004), CCL5 (Lee et al., 
2005; Marella et al., 2004), CCL6, CCL9, and CCL12 (Xiang et al., 2004) have been found to be upregulated. Moreover, induction of the chemokines CXCL9 (Schultz et al., 2004), CXCL10, and CXCL13 (Riemer et al., 2000) is seen at the early, asymptomatic stages of scrapie infection and is sustained at high levels throughout the disease process, possibly indicating an involvement in disease progression. In the periphery, these two groups of chemokines are potent chemoattractants for T cells (Klein et al., 1997) and B cells (Lewicki et al., 2003).

The chemokine receptor CXCR3 is widely expressed in brain tissue and has been found on astrocytes (Biber et al., 2002; Flynn et al., 2003), microglia (Priller et al., 2006), neurons (Omari et al., 2005), and oligodendrocytes (Horuk et al., 2001). Established CXCR3 ligands are CXCL9, CXCL10, and CXCL11. Other chemokines, namely, CCL21 and CXCL13, which are regular ligands of receptor CCR7 and CXCR5, respectively, are also thought to recognize CXCR3 (Jenh et al., 2001; Rappert et al., 2002). CXCR3 has been shown in vitro and in vivo to govern migration but not proliferation of microglia (Flynn et al., 2003; Rappert et al., 2004). In these studies, CXCR3-deficient mice infected with scrapie agents were characterized to determine the consequences of the impairment of microglial migration on disease development. CXCR3-deficient mice showed significantly prolonged survival time of up to 30 days on average. However, they displayed accelerated accumulation of misfolded proteinase K-resistant prion protein $\left(\mathrm{PrP}^{\mathrm{Sc}}\right)$ and 20 times higher infectious prion titres than wild-type mice at the asymptomatic stage of the disease. In CXCR3-deficient animals, microglia activation was found to be reduced and quantitative analysis of gliosis-associated gene expression alterations demonstrated reduction in the number of proinflammatory factors (Riemer et al., 2008). These findings suggested that inflammatory glial responses act in concern with $\mathrm{PrP}^{\mathrm{Sc}}$ in disease development. CXCR3 is crucial for the recruitment of microglia to the inflammatory site of $\operatorname{PrP}^{\mathrm{Sc}}$ deposition.

\section{Neurotoxic prion peptide induces IL-1 $\beta$ production in microglia via inflammasome}

The PrP fragment 106-126 ( $\mathrm{PrP} 106-126)$ is often used as $\mathrm{PrP}^{\mathrm{Sc}}$ neurotoxic peptide in the research of prion disease, because PrP106-126 possesses similar physiochemical and pathological properties to $\mathrm{PrP}^{\mathrm{Sc}}$. PrP106-126 forms amyloid fibrils with a high $\beta$-sheet content, shows partial protease $\mathrm{K}$ resistance, and is neurotoxic in vitro (Henriques et al., 2008; Forloni et al., 1993; Selvaggini et al., 1993).

Extensive research has indicated that the accumulation of aggregated $\mathrm{PrP}^{\mathrm{Sc}}$ leads to activation of microglia, which in turn release superoxide, chemotactic factors, pro-inflammatory cytokines, and neurotoxic factors (Giese et al., 1998; Marella et al., 2004; Rock et al., 2004). In addition, several studies have shown that multiple cytokines and chemokines, such as IL- $1 \beta$, TNF- $\alpha$, and CCL3, were upregulated in the brain from prion-infected mice (Tribouillard-Tanvier et al., 2009). IL-1 $\beta$ plays a crucial role in the regulation of immune and inflammatory responses. It is produced as the inactive precursor pro-IL-1 $\beta$ in the cytosol, and a variety of stimuli lead to higher expression of pro-IL-1 $\beta$ (Dinarello, 2007). Pro-IL-1 $\beta$ is cleaved by caspase- 1 into IL- $1 \beta$, the active mature form. It has recently been reported that neurotoxic prions active mouse microglia and lead to IL- $1 \beta$ production (Peyrin et al., 1999; Yang et al., 2008; Garcao et al., 2006; Crozet et al., 2008). Shi et al., reported that PrP106-126 leads to the formation of NALP3 inflammasome in activated microglia (Shi et al., 2012). 
Inflammasome is a cytosolic protein complex that serves as a platform for activating the proinflammatory cytokines IL-1 $\beta$ and IL-18 via caspase- 1 cleavage (Lamkanfi et al., 2009). The inflammasome plays an important role in innate immunity and is involved in inflammatory disorders. NALP3, one of the most widely researched inflammasomes, consists of NACHT, LRR, and PYD domain-containing proteins, and is a well-known member of the NOD-like receptor family (Mariathasan et al., 2007; Tschopp et al., 2003). In this research, primary microglia cells from neonatal mice were primed with LPS and treated with PrP106-126. PrP106-126 activates caspase- 1 and induces IL- $1 \beta$ release in LPS-primed microglia. The expression of NALP3 and ASC was also upregulated by PrP106-126 stimulation, indicating that neurotoxic prion peptide induces IL- $1 \beta$ via NALP3 inflammasome systems. It appears that inflammasome is a crucial mediator of severe inflammation and neuronal damage induced by microglia infected with prion.

It has recently been reported that CD36 plays an important role in microglial activation and IL-1 $\beta$ production triggered by PrP106-126 stimulation (Kouadir et al., 2012). Blocking CD36 receptor reduces the microglial activation; i.e. the enhanced production of IL- $1 \beta$, TNF- $\alpha$, and IL- 6 associated with PrP106-126 treatment. The relationship of CD36 and inflammasome has not yet been elucidated; however, CD36 may be an important player in the inflammation caused by prion disease.

It has also been reported that NALP3 inflammasome is involved in the innate immune response to $\mathrm{A} \beta$ (Halle et al., 2008). It is widely accepted that the extracellular accumulation of $A \beta$ in senile plaques is a principal event in the pathogenesis of Alzheimer's disease (Weiner et al., 2006; Meyer-Luehmann et al., 2008). Microglia and invading bone marrowderived mononuclear phagocytes are central to the initiation and progression of this disease. Microglia are activated by and recruited to senile plaques, whereupon they phagocytose A $\beta$ and secrete cytokines after activation (Simard et al., 2006). Moreover, systemic inhibition of inflammation or immunization against $\mathrm{A} \beta$ decreases plaque burden and delays disease onset (Weggen et al., 2001; Schenk et al., 1999). One prominent cytokine consistently found in diseased tissues at early stages is IL- $1 \beta$, which has been detected in microglia cells surrounding $A \beta$ plaques in patients with Alzheimer's disease and in animal models of this disease. Similarly to PrP106-126, IL-1 $\beta$ is released from activated microglia in Alzheimer's disease via NALP3 inflammasome. Amyloid protein including $\operatorname{PrP}^{\mathrm{Sc}}$ and $\mathrm{A} \beta$ may activate the inflammasome via a common mechanism. However, it was also reported that the absence of NLRP3 did not significantly change levels of IL-1 $\beta$ in the brain at the terminal stage of the prion disease (Nuvolone et al., 2015). Further studies are required to fully elucidate the detailed mechanism.

\section{Antioxidant cellular prion protein might contribute to control inflammasome in microglia}

Recently, it is reported ROS are essential secondary messengers that trigger NLRP3/ NALP3 inflammasome activation (Dostert et al., 2008; Zhou et al., 2010). ROS production by $\mathrm{H}_{2} \mathrm{O}_{2}$, such as superoxide and hydroxyl radicals, activates the inflammasome, while knockdown of TRX, a cellular antioxidant protein, enhances IL- $1 \beta$ activation by silica, uric acid crystals, and asbestos (Dostert et al., 2009). These findings suggest that oxidative stress could be sufficient to trigger NLRP3/NALP3 activation and the mechanism how NLRP3/ NALP3 senses ROS. ATP-mediated ROS production has been shown to stimulate the PI3K 
pathway, and pharmacological inhibition of PI3K inhibits ATP-mediated caspase-1 activation, suggesting that PI3K may be involved in inflammasome activation downstream of ROS (Cruz et al., 2007). It has also been reported that the non-steroidal anti-inflammatory drug aspirin inhibits the cytotoxicity of prion peptide PrP106-126 to neuronal cells associated with microglia activation in vitro (Yang et al., 2008). ROS are generated mainly via the NADPH oxidase pathway and mitochondria. It has recently been reported that mitochondria control the activation of NLRP3 inflammasome and that the inflammasome activation is negatively regulated by autophagy and positively regulated by ROS. In that study, mitophagy/autophagy blockade led to accumulation of damaged, ROS-generating mitochondria, which in turn activated the NLRP3 inflammasome (Zhou et al., 2010). The putative pathway involved in activation of inflammasome is depicted in Fig. 3.2. It was also reported that NADPH oxidase NOX2 is involved in prion pathogenesis (Sorce et al., 2014). NOX2 is strongly expressed on the microglia of CJD patients and, significantly, NOX2 is expressed around neuronal vacuoles. In this report, mice lacking NOX2 decreased the locomotors deficiency and survived longer after inoculation with $\mathrm{PrP}^{\mathrm{Sc}}$ than those with NOX2.

Oxidation has been shown to be increased by prion infection. In brains from patients with Creutzfeldt-Jakob disease and from Syrian hamsters affected by scrapie, the amounts of glutamic and aminoadipic semialdehydes (products of metal-catalysed oxidation), malondialdehydelysine (a product of lipoxidation), N-epsilon-carboxyethyllysine (a product of glycoxidation), and N-epsilon-carboxymethyllysine (generated by lipoxidation and glycoxidation) were increased. The conversion of $\operatorname{PrP}^{\mathrm{C}}$ into $\mathrm{PrP}^{\mathrm{Sc}}$ was accompanied by alterations in fatty acid composition and increased phosphorylation of ERK(1/2) and p38, protein kinases known to respond to increased levels of ROS (Pamplona et al., 2008).

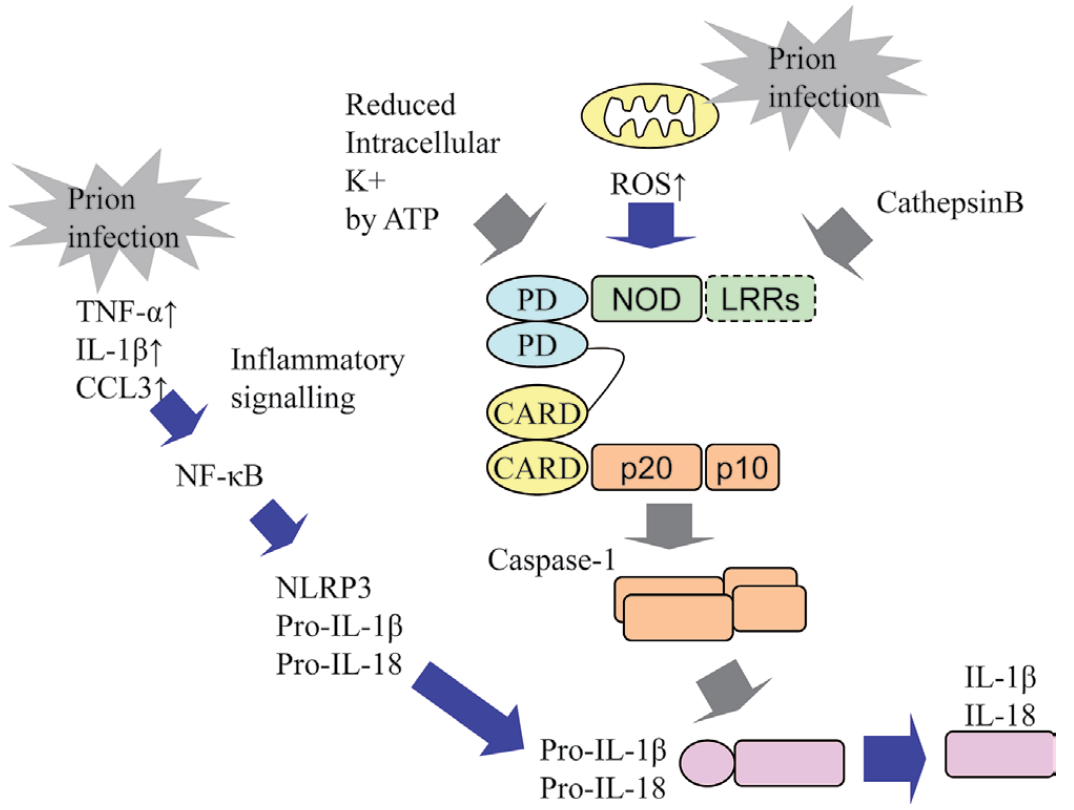

Figure 3.2 The schematic pathway of nlrp3 inflammasome activation. IL-1 $\beta$ is produced via nlrp3 inflammasome activation. nlrp activation is associated with ros production in mitochondria. 
In the $\mathrm{CNS}, \mathrm{PrP}^{\mathrm{C}}$ a cell surface glycoprotein, is expressed mainly in neurons and also in glial cells, and it is an important factor in neurodegenerative prion diseases including bovine spongiform encephalopathy BSE, scrapie, and CJD. Kuwahara et al., reported that $\mathrm{PrP}^{\mathrm{C}}$-deficient neuronal cells die via apoptosis in serum-free medium, which indicates that $\operatorname{PrP}^{\mathrm{C}}$ protects against oxidative stress under conditions of serum deprivation (Kuwahara et al., 1999). Sakudo et al., revealed that $\operatorname{PrP}^{\mathrm{C}}$ has superoxide dismutase activity and protects neurons from oxidative stress (Sakudo et al., 2005). Antioxidant $\operatorname{PrP}^{\mathrm{C}}$ may contribute to suppress inflammasome activation. The relationship between $\operatorname{PrP}^{\mathrm{C}}$ and inflammasome remains to be fully elucidated.

\section{Conclusion}

In this review, the inflammatory reactions of microglia were examined in detail. Inflammatory responses have an important effect on progression of neurodegenerative disorders, but many aspects of the phenomena are not clear. The relationship between neurodegenerative disorders and microglial inflammasome has been elucidated in recent reports. These studies suggested that reactive astrocytes regulated by microglia are closely involved in the brain environment (Liddelow et al., 2017). Further research will elucidate the complicated neuroinflammatory mechanism interacting with microglia, astrocytes and neurons in these neurodegenerative disorders. The regulation of chronic inflammation in the brain is beneficial for to the treatment of neurodegenerative diseases including Alzheimer's disease, Parkinson's disease, Huntington's disease, and prion disease.

\section{References}

Aguzzi, A., and Heikenwalder, M. (2006). Pathogenesis of prion diseases: current status and future outlook. Nat. Rev. Microbiol. 4, 765-775.

Babcock, A.A., Kuziel, W.A., Rivest, S., and Owens, T. (2003). Chemokine expression by glial cells directs leukocytes to sites of axonal injury in the CNS. J. Neurosci. 23, 7922-7930.

Banati, R.B., Daniel, S.E., and Blunt, S.B. (1998). Glial pathology but absence of apoptotic nigral neurons in long-standing Parkinson's disease. Mov. Disord. 13, 221-227. https://doi.org/10.1002/ mds.870130205

Banati, R.B., Gehrmann, J., Schubert, P., and Kreutzberg, G.W. (1993). Cytotoxicity of microglia. Glia 7, 111-118. https://doi.org/10.1002/glia.440070117

Biber, K., Dijkstra, I., Trebst, C., De Groot, C.J., Ransohoff, R.M., and Boddeke, H.W. (2002). Functional expression of CXCR3 in cultured mouse and human astrocytes and microglia. Neuroscience 112, 487-497.

Block, M.L., Zecca, L., and Hong, J.S. (2007). Microglia-mediated neurotoxicity: uncovering the molecular mechanisms. Nat. Rev. Neurosci. 8, 57-69.

Bsibsi, M., Ravid, R., Gveric, D., and van Noort, J.M. (2002). Broad expression of Toll-like receptors in the human central nervous system. J. Neuropathol. Exp. Neurol. 61, 1013-1021.

Carroll, J.A., Striebel, J.F., Race, B., Phillips, K., and Chesebro, B. (2015). Prion infection of mouse brain reveals multiple new upregulated genes involved in neuroinflammation or signal transduction. J Virol. 89, 2388-2404.

Chan, W.Y., Kohsaka, S., and Rezaie, P. (2007). The origin and cell lineage of microglia: new concepts. Brain Res. Rev. 53, 344-354.

Crozet, C., Beranger, F., and Lehmann, S. (2008). Cellular pathogenesis in prion diseases. Vet. Res. 39, 44. https://doi.org/10.1051/vetres:2008021

Cruz, C.M., Rinna, A., Forman, H.J., Ventura, A.L., Persechini, P.M., and Ojcius, D.M. (2007). ATP activates a reactive oxygen species-dependent oxidative stress response and secretion of proinflammatory cytokines in macrophages. J. Biol. Chem. 282, 2871-2879. 
Dheen, S.T., Kaur, C., and Ling, E.A. (2007). Microglial activation and its implications in the brain diseases. Curr. Med. Chem. 14, 1189-1197.

Dinarello, C.A. (2007). A signal for the caspase-1 inflammasome free of TLR. Immunity 26, 383-385.

Dostert, C., Guarda, G., Romero, J.F., Menu, P., Gross, O., Tardivel, A., Suva, M.L., Stehle, J.C., Kopf, M., Stamenkovic, I., et al. (2009). Malarial hemozoin is a Nalp3 inflammasome activating danger signal. PLOS ONE 4, e6510. https://doi.org/10.1371/journal.pone.0006510

Dostert, C., Pétrilli, V., Van Bruggen, R., Steele, C., Mossman, B.T., and Tschopp, J. (2008). Innate immune activation through Nalp3 inflammasome sensing of asbestos and silica. Science 320, 674-7. https:// doi.org/10.1126/science.1156995

Etminan, M., Gill, S., and Samii, A. (2003). Effect of non-steroidal anti-inflammatory drugs on risk of Alzheimer's disease: systematic review and meta-analysis of observational studies. BMJ 327, 128. https://doi.org/10.1136/bmj.327.7407.128

Felton, L.M., Cunningham, C., Rankine, E.L., Waters, S., Boche, D., and Perry, V.H. (2005). MCP-1 and murine prion disease: separation of early behavioural dysfunction from overt clinical disease. Neurobiol. Dis. 20, 283-295.

Floden, A.M., Li, S., and Combs, C.K. (2005). Beta-amyloid-stimulated microglia induce neuron death via synergistic stimulation of tumor necrosis factor alpha and NMDA receptors. J. Neurosci. 25, 2566-2575.

Flynn, G., Maru, S., Loughlin, J., Romero, I.A., and Male, D. (2003). Regulation of chemokine receptor expression in human microglia and astrocytes. J. Neuroimmunol. 136, 84-93.

Forloni, G., Angeretti, N., Chiesa, R., Monzani, E., Salmona, M., Bugiani, O., and Tagliavini, F. (1993). Neurotoxicity of a prion protein fragment. Nature 362, 543-546. https://doi.org/10.1038/362543a0

Garção, P., Oliveira, C.R., and Agostinho, P. (2006). Comparative study of microglia activation induced by amyloid-beta and prion peptides: role in neurodegeneration. J. Neurosci. Res. 84, 182-193. https:// doi.org/10.1002/jnr.20870

Giese, A., Brown, D.R., Groschup, M.H., Feldmann, C., Haist, I., and Kretzschmar, H.A. (1998). Role of microglia in neuronal cell death in prion disease. Brain Pathol. 8, 449-457.

González-Scarano, F., and Baltuch, G. (1999). Microglia as mediators of inflammatory and degenerative diseases. Annu. Rev. Neurosci. 22, 219-240. https://doi.org/10.1146/annurev.neuro.22.1.219

Graeber, M.B. (2010). Changing face of microglia. Science 330, 783-8. https://doi.org/10.1126/ science.1190929

Griffin, W.S., Stanley, L.C., Ling, C., White, L., MacLeod, V., Perrot, L.J., White, C.L., and Araoz, C. (1989). Brain interleukin 1 and S-100 immunoreactivity are elevated in Down syndrome and Alzheimer disease. Proc. Natl. Acad. Sci. U.S.A. 86, 7611-7615.

Halle, A., Hornung, V., Petzold, G.C., Stewart, C.R., Monks, B.G., Reinheckel, T., Fitzgerald, K.A., Latz, E., Moore, K.J., and Golenbock, D.T. (2008). The NALP3 inflammasome is involved in the innate immune response to amyloid-beta. Nat. Immunol. 9, 857-865. https://doi.org/10.1038/ni.1636

Hartlage-Rubsamen, M., Lemke, R., and Schiliebs, R. (1999). Interleukin-1 beta, inducible nitric oxide synthase, and nuclear factor-kappaB are induced in morphologically distinct microglia after rat hippocampal lipopolysaccharide/interferon-gamma injection. J. Neurosci. Res. 57, 388-398.

Henriques, S.T., Pattenden, L.K., Aguilar, M.I., and Castanho, M.A.R.B. (2008). PrP (106-126) does not interact with membranes under physiological conditions. Biophys. J. 95, 1877-1889.

Hines, D.J., Hines, R.M., Mulligan, S.J., and Macvicar, B.A. (2009). Microglia processes block the spread of damage in the brain and require functional chloride channels. Glia 57, 1610-1618. https://doi. org/10.1002/glia.20874

Horuk, R. (2001). Chemokine receptors. Cytokine Growth Factor Rev. 12, 313-335.

Imai, F., Suzuki, H., Oda, J., Ninomiya, T., Ono, K., Sano, H., and Sawada, M. (2007). Neuroprotective effect of exogenous microglia in global brain ischemia. J. Cereb. Blood Flow Metab. 27, 488-500.

Ironside, J.W. (1998). Prion diseases in man. J. Pathol. 186, 227-234.

Jenh, C.H., Cox, M.A., Hipkin, W., Lu, T., Pugliese-Sivo, C., Gonsiorek, W., Chou, C.C., Narula, S.K., and Zavodny, P.J. (2001). Human B cell-attracting chemokine 1 (BCA-1; CXCL13) is an agonist for the human CXCR3 receptor. Cytokine 15, 113-121. https://doi.org/10.1006/cyto.2001.0923

Klein, M.A., Frigg, R., Flechsig, E., Raeber, A.J., Kalinke, U., Bluethmann, H., Bootz, F., Suter, M., Zinkernagel, R.M., and Aguzzi, A. (1997). A crucial role for B cells in neuroinvasive scrapie. Nature 390, 687-690. https://doi.org/10.1038/37789

Kouadir, M., Yang, L., Tan, R., Shi, F., Lu, Y., Zhang, S., Yin, X., Zhou, X., and Zhao, D. (2012). CD36 participates in $\operatorname{PrP}(106-126)$-induced activation of microglia. PLOS ONE 7, e30756. https://doi. org/10.1371/journal.pone.0030756 
Kreutzberg, G.W. (1996). Microglia: a sensor for pathological events in the CNS. Trends Neurosci. 19, 312-318.

Kuwahara, C., Takeuchi, A.M., Nishimura, T., Haraguchi, K., Kubosaki, A., Matsumoto, Y., Saeki, K., Matsumoto, Y., Yokoyama, T., Itohara, S., et al. (1999). Prions prevent neuronal cell-line death. Nature 400, 225-226. https://doi.org/10.1038/22241

Lamkanfi, M., and Dixit, V.M. (2009). The inflammasomes. PLOS Pathog. 5, e1000510.

Lee, H.P., Jun, Y.C., Choi, J.K., Kim, J.I., Carp, R.I., and Kim, Y.S. (2005). The expression of RANTES and chemokine receptors in the brains of scrapie-infected mice. J. Neuroimmunol. 158, 26-33.

Lewicki, H., Tishon, A., Homann, D., Mazarguil, H., Laval, F., Asensio, V.C., Campbell, I.L., DeArmond, S., Coon, B., Teng, C., et al. (2003). T cells infiltrate the brain in murine and human transmissible spongiform encephalopathies. J. Virol. 77, 3799-3808.

Li, H., and Cuzner, M.L., (1996). Newcombe, J. Microglial-derived macrophages in early multiple sclerosis plaques. Neuropathol. Appl. Neurobiol. 22, 207-215.

Liddelow, S.A., Guttenplan, K.A., Clarke, L.E., Bennett, F.C., Bohlen, C.J., Schirmer, L., Bennett, M.L., Münch, A.E., Chung, W.S., Peterson, T.C., et al. (2017). Neurotoxic reactive astrocytes are induced by activated microglia. Nature 541, 481-487. https://doi.org/10.1038/nature21029

Lu, Z.Y., Baker, C.A., and Manuelidis, L. (2004). New molecular markers of early and progressive CJD brain infection. J. Cell. Biochem. 93, 644-652. https://doi.org/10.1002/jcb.20220

Marella, M., and Chabry,J. (2004). Neurons and astrocytes respond to prion infection by inducing microglia recruitment. J. Neurosci. 24, 620-627. https://doi.org/10.1523/JNEUROSCI.4303-03.2004

Mariathasan, S., and Monack, D.M. (2007). Inflammasome adaptors and sensors: intracellular regulators of infection and inflammation. Nat. Rev. Immunol. 7, 31-40.

McGeer, P.L., Itagaki, S., Boyes, B.E., and McGeer, E.G. (1988). Reactive microglia are positive for HLA-DR in the substantia nigra of Parkinson's and Alzheimer's disease brains. Neurology 38, 1285-1291.

McGeer, P.L., Itagaki, S., and McGeer, E.G. (1988). Expression of the histocompatibility glycoprotein HLA-DR in neurological disease. Acta Neuropathol. 76, 550-557.

Meyer-Luehmann, M., Spires-Jones, T.L., Prada, C., Garcia-Alloza, M., de Calignon, A., Rozkalne, A., Koenigsknecht-Talboo, J., Holtzman, D.M., Bacskai, B.J., and Hyman, B.T. (2008). Rapid appearance and local toxicity of amyloid-beta plaques in a mouse model of Alzheimer's disease. Nature 451, 720-724. https://doi.org/10.1038/nature06616

Neumann, J., Gunzer, M., Gutzeit, H.O., Ullrich, O., Reymann, K.G., and Dinkel, K. (2006). Microglia provide neuroprotection after ischemia. FASEB J. 20, 714-716.

Nuvolone, M., Sorce, S., Schwarz, P., and Aguzzi, A. (2015). Prion pathogenesis in the absence of NLRP3/ ASC inflammasomes. PLOS ONE 10, e0117208. https://doi.org/10.1371/journal.pone.0117208

Omari, K.M., John, G.R., Sealfon, S.C., and Raine, C.S. (2005). CXC chemokine receptors on human oligodendrocytes: implications for multiple sclerosis. Brain 128, 1003-1015.

Pamplona, R., Naudí, A., Gavín, R., Pastrana, M.A., Sajnani, G., Ilieva, E.V., Del Río, J.A., Portero-Otín, M., Ferrer, I., and Requena, J.R. (2008). Increased oxidation, glycoxidation, and lipoxidation of brain proteins in prion disease. Free Radic. Biol. Med. 45, 1159-1166. https://doi.org/10.1016/j. freeradbiomed.2008.07.009

Parkhurst, C.N., Yang, G., Ninan, I., Savas, J.N., Yates, J.R., Lafaille, J.J., Hempstead, B.L., Littman, D.R., and Gan, W.B. (2013). Microglia promote learning-dependent synapse formation through brain-derived neurotrophic factor. Cell 155, 1596-1609. https://doi.org/10.1016/j.cell.2013.11.030

Perry, V.H., Nicoll, J.A., and Holmes, C. (2010). Microglia in neurodegenerative disease. Nat. Rev. Neurol. 6, 193-201. https://doi.org/10.1038/nrneurol.2010.17

Peyrin, J.M., Lasmézas, C.I., Haïk, S., Tagliavini, F., Salmona, M., Williams, A., Richie, D., Deslys, J.P., and Dormont, D. (1999). Microglial cells respond to amyloidogenic PrP peptide by the production of inflammatory cytokines. Neuroreport 10, 723-729.

Power, J.H., and Blumbergs, P.C. (2009). Cellular glutathione peroxidase in human brain: cellular distribution, and its potential role in the degradation of Lewy bodies in Parkinson's disease and dementia with Lewy bodies. Acta Neuropathol. 117, 63-73. https://doi.org/10.1007/s00401-008-0438-3

Priller, J., Prinz, M., Heikenwalder, M., Zeller, N., Schwarz, P., Heppner, F.L., and Aguzzi, A. (2006). Early and rapid engraftment of bone marrow-derived microglia in scrapie. J. Neurosci. 26, 11753-11762.

Prusiner, S.B. (1998). Prions. Proc. Natl. Acad. Sci. U.S.A. 95, 13363-13383.

Raine, C.S. (1994). Multiple sclerosis: immune system molecule expression in the central nervous system. J. Neuropathol. Exp. Neurol. 53, 328-337.

Ransohoff, R.M., and Perry, V.H. (2009). Microglial physiology: unique stimuli, specialized responses. Annu. Rev. Immunol. 27, 119-145. https://doi.org/10.1146/annurev.immunol.021908.132528 
Rappert, A., Bechmann, I., Pivneva, T., Mahlo, J., Biber, K., Nolte, C., Kovac, A.D., Gerard, C., Boddeke, H.W., Nitsch, R., et al. (2004). CXCR3-dependent microglial recruitment is essential for dendrite loss after brain lesion. J. Neurosci. 24, 8500-8509. https://doi.org/10.1523/JNEUROSCI.2451-04.2004

Rappert, A., Biber, K., Nolte, C., Lipp, M., Schubel, A., Lu, B., Gerard, N.P., Gerard, C., Boddeke, H.W., and Kettenmann, H. (2002). Secondary lymphoid tissue chemokine (CCL21) activates CXCR3 to trigger a Cl- current and chemotaxis in murine microglia. J. Immunol. 168, 3221-3226.

Riemer, C., Neidhold, S., Burwinkel, M., Schwarz, A., Schultz, J., Krätzschmar, J., Mönning, U., and Baier, M. (2004). Gene expression profiling of scrapie-infected brain tissue. Biochem. Biophys. Res. Commun. 323, 556-564. https://doi.org/10.1016/j.bbrc.2004.08.124

Riemer, C., Queck, I., Simon, D., Kurth, R., and Baier, M. (2000). Identification of upregulated genes in scrapie-infected brain tissue. J. Virol. 74, 10245-10248.

Riemer, C., Schultz, J., Burwinkel, M., Schwarz, A., Mok, S.W., Gültner, S., Bamme, T., Norley, S., van Landeghem, F., Lu, B., et al. (2008). Accelerated prion replication in, but prolonged survival times of, prion-infected CXCR3-/- mice. J. Virol. 82, 12464-12471. https://doi.org/10.1128/JVI.01371-08

Rock, R.B., Gekker, G., Hu, S., Sheng, W.S., Cheeran, M., Lokensgard, J.R., and Peterson, P.K. (2004). Role of microglia in central nervous system infections. Clin. Microbiol. Rev. 17, 942-964, table of contents.

Sakudo, A., Lee, D.C., Nishimura, T., Li, S., Tsuji, S., Nakamura, T., Matsumoto, Y., Saeki, K., Itohara, S., Ikuta, K., et al. (2005). Octapeptide repeat region and N-terminal half of hydrophobic region of prion protein $(\mathrm{PrP})$ mediate PrP-dependent activation of superoxide dismutase. Biochem. Biophys. Res. Commun. 326, 600-606.

Sapp, E., Kegel, K.B., Aronin, N., Hashikawa, T., Uchiyama, Y., Tohyama, K., Bhide, P.G., Vonsattel, J.P., and DiFiglia, M. (2001). Early and progressive accumulation of reactive microglia in the Huntington disease brain. J. Neuropathol. Exp. Neurol. 60, 161-172.

Schenk, D., Barbour, R., Dunn, W., Gordon, G., Grajeda, H., Guido, T., Hu, K., Huang, J., Johnson-Wood, K., Khan, K., et al. (1999). Immunization with amyloid-beta attenuates Alzheimer-disease-like pathology in the PDAPP mouse. Nature 400, 173-177. https://doi.org/10.1038/22124

Schultz, J., Schwarz, A., Neidhold, S., Burwinkel, M., Riemer, C., Simon, D., Kopf, M., Otto, M., and Baier, M. (2004). Role of interleukin-1 in prion disease-associated astrocyte activation. Am. J. Pathol. 165, 671-678

Selvaggini, C., De Gioia, L., Cantù, L., Ghibaudi, E., Diomede, L., Passerini, F., Forloni, G., Bugiani, O., Tagliavini, F., and Salmona, M. (1993). Molecular characteristics of a protease-resistant, amyloidogenic and neurotoxic peptide homologous to residues 106-126 of the prion protein. Biochem. Biophys. Res. Commun. 194, 1380-1386.

Shi, F., Yang, L., Kouadir, M., Yang, Y., Wang, J., Zhou, X., Yin, X., and Zhao, D. (2012). The NALP3 inflammasome is involved in neurotoxic prion peptide-induced microglial activation. J. Neuroinflammation 9, 73. https://doi.org/10.1186/1742-2094-9-73

Simard, A.R., Soulet, D., Gowing, G., Julien, J.P., and Rivest, S. (2006). Bone marrow-derived microglia play a critical role in restricting senile plaque formation in Alzheimer's disease. Neuron 49, 489-502.

Sitte, H.H., Wanschitz, J., Budka, H., and Berger, M.L. (2001). Autoradiography with [3H]PK11195 of spinal tract degeneration in amyotrophic lateral sclerosis. Acta Neuropathol. 101, 75-78.

Sorce, S., Nuvolone, M., Keller, A., Falsig, J., 7Varol, A., Schwarz, P., Bieri, M., Budka, H., and Aguzzi, A. (2014). The role of the NADPH oxidase NOX2 in prion pathogenesis. PLOS Pathog. 10, e1004531. https://doi.org/10.1371/journal.ppat.1004531

Suzumura, A., Sawada, M., and Marunouchi, T. (1996). Selective induction of interleukin-6 in mouse microglia by granulocyte-macrophage colony-stimulating factor. Brain Res. 713, 192-198.

Takami, S., Nishikawa, H., Minami, M., Nishiyori, A., Sato, M., Akaike, A., and Satoh, M. (1997). Induction of macrophage inflammatory protein MIP-1 alpha mRNA on glial cells after focal cerebral ischemia in the rat. Neurosci. Lett. 227, 173-176.

Tribouillard-Tanvier, D., Striebel, J.F., Peterson, K.E., and Chesebro, B. (2009). Analysis of protein levels of 24 cytokines in scrapie agent-infected brain and glial cell cultures from mice differing in prion protein expression levels. J. Virol. 83, 11244-11253. https://doi.org/10.1128/JVI.01413-09

Tschopp, J., Martinon, F., and Burns, K. (2003). NALPs: a novel protein family involved in inflammation. Nat. Rev. Mol. Cell Biol. 4, 95-104. https://doi.org/10.1038/nrm1019

van Rossum, D., and Hanisch, U.K. (2004). Microglia. Metab. Brain. Dis. 19, 393-411.

Vincenti, J.E., Murphy, L., Grabert, K., McColl, B.W., Cancellotti, E., Freeman, T.C., and Manson, J.C. (2015). Defining the microglia response during the time course of chronic neurodegeneration. J. Virol. 90, 3003-17. https://doi.org/10.1128/JVI.02613-15 
Vlad, S.C., Miller, D.R., Kowall, N.W., and Felson, D.T. (2008). Protective effects of NSAIDs on the development of Alzheimer disease. Neurology 70, 1672-167. https://doi.org/10.1212/01. wnl.0000311269.57716.63

Wechselberger, C., Wurm, S., Pfarr, W., and Höglinger, O. (2002). The physiological functions of prion protein. Exp. Cell Res. 281, 1-8.

Weggen, S., Eriksen, J.L., Das, P., Sagi, S.A., Wang, R., Pietrzik, C.U., Findlay, K.A., Smith, T.E., Murphy, M.P., Bulter, T., et al. (2001). A subset of NSAIDs lower amyloidogenic Abeta42 independently of cyclooxygenase activity. Nature 414, 212-216. https://doi.org/10.1038/35102591

Weiner, H.L., and Frenkel, D. (2006). Immunology and immunotherapy of Alzheimer's disease. Nat. Rev. Immunol. 6, 404-416.

Xiang, W., Windl, O., Wünsch, G., Dugas, M., Kohlmann, A., Dierkes, N., Westner, I.M., and Kretzschmar, H.A. (2004). Identification of differentially expressed genes in scrapie-infected mouse brains by using global gene expression technology. J. Virol. 78, 11051-11060. https://doi.org/10.1128/ JVI.78.20.11051-11060.2004

Yang, L., Zhou, X., Yang, J., Yin, X., Han, L., and Zhao, D. (2008). Aspirin inhibits cytotoxicity of prion peptide PrP106-126 to neuronal cells associated with microglia activation in vitro. J. Neuroimmunol. 199, 10-7. https://doi.org/10.1016/j.jneuroim.2008.04.028

Zhou, R., Tardivel, A., Thorens, B., Choi, I., and Tschopp, J. (2010). Thioredoxin-interacting protein links oxidative stress to inflammasome activation. Nat. Immunol. 11, 136-140. https://doi.org/10.1038/ ni. 1831

Zhou, R., Yazdi, A.S., Menu, P., and Tschopp, J. (2011). A role for mitochondria in NLRP3 inflammasome activation. Nature 469, 221-225. https://doi.org/10.1038/nature09663 
